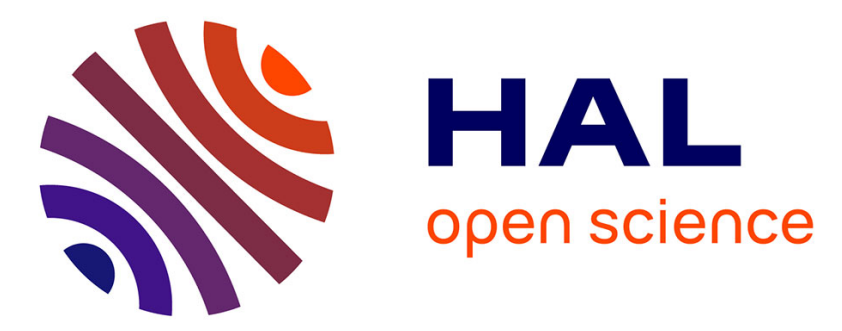

\title{
Impact of wind power generating system integration on frequency stabilization in multi-area power system with fuzzy logic controller in deregulated environment
} Y. K. Bhateshvar, H. D. Mathur, H. Siguerdidjane

\section{- To cite this version:}

Y. K. Bhateshvar, H. D. Mathur, H. Siguerdidjane. Impact of wind power generating system integration on frequency stabilization in multi-area power system with fuzzy logic controller in deregulated environment. Frontiers in Energy, 2015, 9 (1), pp.7-21. 10.1007/s11708-014-0338-2 . hal-01258062

HAL Id: hal-01258062

https://hal-centralesupelec.archives-ouvertes.fr/hal-01258062

Submitted on 29 Mar 2020

HAL is a multi-disciplinary open access archive for the deposit and dissemination of scientific research documents, whether they are published or not. The documents may come from teaching and research institutions in France or abroad, or from public or private research centers.
L'archive ouverte pluridisciplinaire HAL, est destinée au dépôt et à la diffusion de documents scientifiques de niveau recherche, publiés ou non, émanant des établissements d'enseignement et de recherche français ou étrangers, des laboratoires publics ou privés. 


\title{
Impact of Wind Power Generating System Integration on Frequency Stabilization in Multi-area Power System with Fuzzy Logic Controller in Deregulated Environment
}

\author{
Y.K. Bhateshvar ${ }^{1}$, H.D. Mathur ${ }^{1}$ and H. Siguerdidjane ${ }^{2}$ \\ ${ }^{1}$ Department of Electrical and Electronics Engineering, \\ Birla Institute of Technology and Science, Pilani, \\ Rajasthan 333031, India \\ ${ }^{2}$ Automatic Control Department \\ Supélec, France \\ yogeshbhateshvar@gmail.com,mathurhd@gmail.com and houria.siguerdidjane@supelec.fr
}

\begin{abstract}
Amongst the available options for renewable energy integration in existing power system, wind power is being considered as one of the suited options for future electrical power generation. The major constraint of wind power generating system (WPGS) for not being preferred for frequency stabilization as it does not provide inertial support because of power electronic converters in between grid and WPGS. The proposed control strategy suggests a substantial contribution to system inertia in terms of short term active power support in a two area restructured power system. The control scheme uses fuzzy logic based design and takes frequency deviation as input to provide quick active power support, which balances the drop in frequency and tie-line power during transient conditions. This paper presents a comprehensive study on the wind power impact with increasing wind power penetration on frequency stabilization in restructured power system scenario. Varying load conditions are also analysed in simulation studies for the same power system model with proposed control scheme. Simulation results advocates the justification of control scheme over other schemes.
\end{abstract}

Keywords- Two Area Power System, Automatic Generation Control, Wind Power Generating System, Deregulated Environment, Fuzzy Logic Controller.

\section{INTRODUCTION}

Reduction of fossil fuel-based energy has been among the top priority goals of regulatory agencies around the world. Therefore, there is an urgent need to exploit more sources of renewable energy. Particularly wind energy is one of the most promising options among renewable sources of energy. For areas with abundance wind power potentials, wind energy is gradually replacing the capacity of the conventional fossil fuel generating units. Wind power generation is highly important and challenging compared to conventional sources of energy since availability of the wind energy source is unpredictable and not controllable. Therefore, an efficient integration of large amounts of wind turbines into the existing electrical networks can significantly impact for grid stability. It has been noticed that without a suitable control strategy, full integration of wind energy with high penetration would not be possible particularly in ancillary services such as frequency regulation.

This paper attempts to study and examine the role of WPGS for wind power generation in frequency and tie line power oscillation control with different levels of wind penetration into the system. The fuzzy logic based WPGS control system is developed for two-area restructured interconnected system. It has been observed that little emphasis has been given in the concept of inertial support by WPGS in order to minimize inter area oscillations in restructured power system. The concept of releasing the kinetic energy of a WPGS when the frequency of the power system is reduced in order to prevent the reduction of system inertia is presented in [1]. The experimental results of a Doubly Fed Induction Generator (DFIG)-based wind turbine using converters [2], modelling of variable-speed wind turbine concepts in power system dynamic simulations [3] and impact assessment of high penetration of wind energy to the Irish network [4] are also available in literature. Frequency regulation and inertial support is also discussed in [5-6]. The proposed work adopts a systematic approach to address this issue of frequency and tie-line oscillations in modern power system. The steps listed below are followed;

1. Development of mathematical model of two area system in deregulated environment.

2. Wind power generating system modelling with inertial support feature.

3. Intelligent control strategies for frequency regulation.

4. Simulation and analysis of different cases for varying load and wind power penetration with different sets of conventional generators. 


\begin{tabular}{|ll|}
\hline Abbreviations: & \\
GENCOs & Generation Companies \\
DISCOs & Distribution Companies \\
ACE & Area Control Error \\
APFM & Area Participation Factor Matrix \\
CPFM & Contract Participation Factor Matrix \\
ISE & Integration of Square of Error \\
WPGS & Wind Power Generating System \\
GAI & Genetic Algorithm optimized Integral Controller \\
PI & Proportional Integral \\
FLC & Fuzzy Logic Controller \\
MISO & Multiple Input and Single Output \\
WT & Wind Turbine \\
TT-TTW & Thermal-Thermal with wind power connected in area 2 \\
TTW-TTW & Thermal-Thermal with wind power connected in both areas \\
TT-HHW & Thermal-Hydro with wind power connected in area 2 \\
TTW-HHW & Thermal-Hydro with wind power connected in both areas \\
\hline
\end{tabular}

\section{SYSTEM MODELING}

\subsection{Mathematical Model of Two-Area Power System in Deregulated Environment}

The system examined consists of two control area and each having two GENCOs and two DISCOs. In this study, reheat thermal and hydro based generating units considered as conventional generating units. In first and second case, the Control area 1 composed of two reheat thermal GENCOs of equal capacity and control area 2 composed of two hydro GENCOs of equal capacity as shown in Fig. 1. In third case, different combinations of various GENCOs with WPGS are taken into consideration.

The model is considered in continuous operation. System parameters used for study are given in appendix. In restructured environment, the concept of CPFM makes the visualization of contracts. In CPFM, the number of rows indicates number of GENCOs and the number of columns indicates DISCOs [7] and sum of all cpfs is unity in a column of matrix.

\begin{tabular}{|c|c|c|c|c|c|c|}
\hline \multirow{8}{*}{ CPFM $=$} & \multicolumn{2}{|c|}{ Area-I } & \multicolumn{2}{|c|}{ Area-I to Area-II } & \multirow{3}{*}{$\begin{array}{l}G 1 \\
G 2 \\
\end{array}$} & \\
\hline & \multirow{2}{*}{$\begin{array}{l}c p f \\
c p f\end{array}$} & \multirow{2}{*}{$\begin{array}{l}c p f_{12} \\
c p f_{22}\end{array}$} & \multirow{2}{*}{$\begin{array}{l}c p f_{13} \\
c p f_{23}\end{array}$} & \multirow{2}{*}{$\begin{array}{l}c p f_{14} \\
c p f_{24}\end{array}$} & & \multirow{4}{*}{$\begin{array}{l}\text { Tि } \\
\text { 竞 } \\
\end{array}$} \\
\hline & & & & & & \\
\hline & \multirow{2}{*}{$\begin{array}{l}c p f_{3} \\
c p f_{4}\end{array}$} & $c p f_{32}$ & \multirow{2}{*}{$\begin{array}{l}c p f_{33} \\
c p f_{43} \\
\end{array}$} & \multirow{2}{*}{$\begin{array}{l}c p f_{34} \\
c p f_{44}\end{array}$} & G3 & \\
\hline & & $c p f_{42}$ & & & G4 & \\
\hline & \multicolumn{2}{|c|}{ Area-II to Area-I } & \multicolumn{2}{|c|}{ Area-II } & & \\
\hline & D1 & D2 & D3 & D4 & & \\
\hline & \multicolumn{4}{|c|}{ DISCO's } & & \\
\hline
\end{tabular}




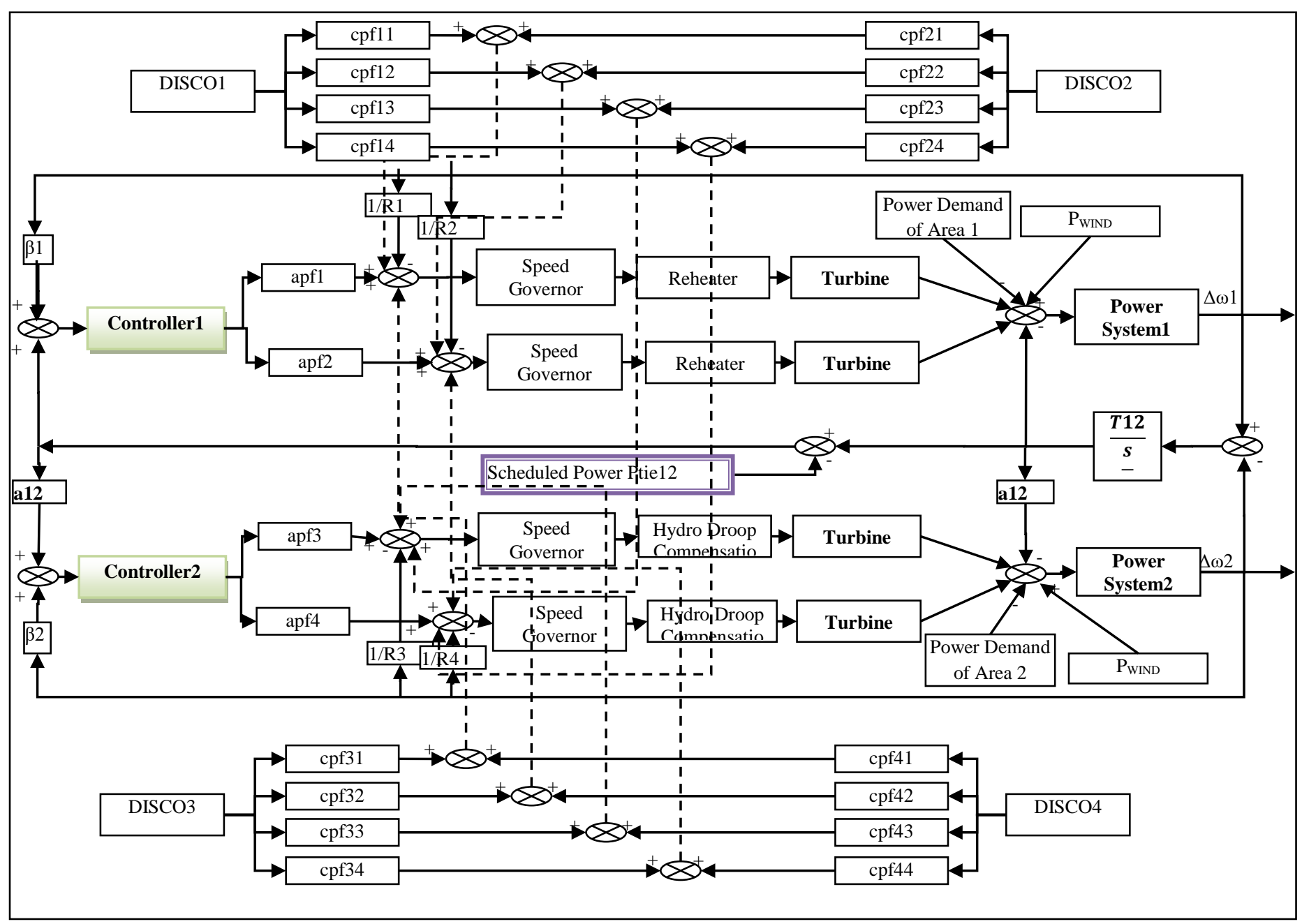

Fig. 1 Complete System model of Load Frequency Control of Two Area Thermal thermal-Hydro hydro power system in Deregulated Environment

The frequency regulation depends on the control signal that composed of tie-line deviation and weighted frequency deviation. It is called as ACE, as shown in Eq. (1)

$$
\mathrm{ACE}_{\mathrm{i}}=\Delta \mathrm{P}_{\mathrm{tie}, \mathrm{i}}+\beta_{\mathrm{i}} \Delta \mathrm{f}_{\mathrm{i}}
$$

Where, $\beta_{\mathrm{i}}$ is frequency bias constant, $\Delta \mathrm{f}_{\mathrm{i}}$ frequency deviation and $\Delta \mathrm{P}_{\text {tie }}$ is change in tie line power for $\mathrm{i}^{\text {th }}$ area [8]. In deregulated environment, within a control area ACE again distributed among several GENCOs by coefficients termed as ACE participation factors (apfs). The APFM is shown in Eq. (2). Within a control area, all apf's addition is equal to1.

$$
\mathrm{APFM}=\left[\begin{array}{cccc}
\mathrm{apf}_{1} & 0 & 0 & 0 \\
0 & \mathrm{apf}_{2} & 0 & 0 \\
0 & 0 & \mathrm{apf}_{3} & 0 \\
0 & 0 & 0 & \mathrm{apf}_{4}
\end{array}\right]
$$

The contracted scheduled loads in DISCOs in area 1 are $\Delta \mathrm{P}_{\mathrm{Ld} 1 \text { C Cont }}$ and $\Delta \mathrm{P}_{\mathrm{Ld} 2 \text { CCont }}$ and in area 2 are $\Delta \mathrm{P}_{\mathrm{Ld} 3 \_ \text {Cont }}$ and $\Delta \mathrm{P}_{\mathrm{Ld} 4 \text { _Cont }}$ and these are shown in the $\Delta \mathrm{P}_{\mathrm{LD}_{-} \text {Cont }}$ matrix. The uncontracted local loads in DISCOs in area 1 are $\Delta \mathrm{P}_{\mathrm{Ld} 1_{-} \text {Uncont }} \& \Delta \mathrm{P}_{\mathrm{Ld} \text { 2_Uncont }_{3}}$ and in area 2 are $\Delta \mathrm{P}_{\mathrm{Ld} 3_{-} \text {Uncont }} \& \Delta \mathrm{P}_{\mathrm{Ld} 4 \_ \text {Uncont }}$ shown in $\Delta \mathrm{P}_{\mathrm{LD} \_ \text {Uncont }}$ matrix [9]. 


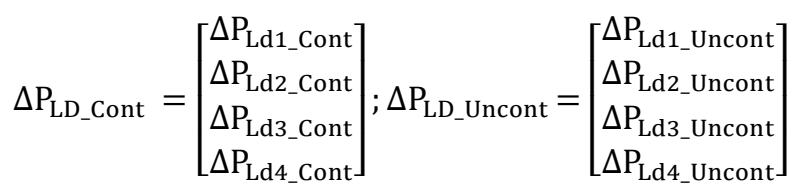

The total demanded load power $\Delta \mathrm{P}_{\mathrm{LD}}$ is represented by Eq. (3):

$$
\Delta \mathrm{P}_{\mathrm{LD}}=\Delta \mathrm{P}_{\mathrm{LD} \_ \text {Cont }}+\Delta \mathrm{P}_{\mathrm{LD} \text { _Uncont }}
$$

Similarly, the contracted generated powers in area 1 are $\Delta \mathrm{P}_{\mathrm{g} 1_{-} \text {Cont }} \& \Delta \mathrm{P}_{\mathrm{g} 2 \_ \text {Cont }}$ and in area 2 are $\Delta \mathrm{P}_{\mathrm{g} 3 \_ \text {Cont }} \& \Delta \mathrm{P}_{\mathrm{g}_{-} \text {Cont }}$ given in $\Delta \mathrm{P}_{\mathrm{G}_{-} \text {Cont }}$ matrix. $\Delta \mathrm{P}_{\mathrm{g} 1_{1} \text { Uncont }} \& \Delta \mathrm{P}_{\mathrm{g} 2 \text { Uncont }}$ are uncontracted generated powers from area 1 and $\Delta \mathrm{P}_{\text {g3_Uncont }} \& \Delta \mathrm{P}_{\text {g }_{-} \text {Uncont }}$ are uncontracted generated powers from area 2 as in $\Delta \mathrm{P}_{\mathrm{G}_{-} \text {Cont }}$ matrix.

$$
\Delta \mathrm{P}_{\mathrm{G}_{-} \text {Cont }}=\left[\begin{array}{c}
\Delta \mathrm{P}_{\mathrm{g}_{1} \text { Cont }} \\
\Delta \mathrm{P}_{\mathrm{g}_{2} \text { Cont }} \\
\Delta \mathrm{P}_{\mathrm{g}_{3} \text { Cont }} \\
\Delta \mathrm{P}_{\mathrm{g}_{3} \text { Cont }}
\end{array}\right] ; \Delta \mathrm{P}_{\mathrm{G}_{-} \text {Uncont }}=\left[\begin{array}{c}
\Delta \mathrm{P}_{\mathrm{g}_{1} \text { Uncont }} \\
\Delta \mathrm{P}_{\mathrm{g}_{2} \text { Uncont }} \\
\Delta \mathrm{P}_{\mathrm{g}_{3} \text { Uncont }} \\
\Delta \mathrm{P}_{\mathrm{g}_{4} \text { Uncont }}
\end{array}\right]
$$

Contracted generated power by GENCOs, $\Delta \mathrm{P}_{\mathrm{G}_{-} \text {Cont }}$ is calculated as Eq. (4):

$$
\Delta \mathrm{P}_{\mathrm{G}_{-} \text {Cont }}=\mathrm{CPFM} * \Delta \mathrm{P}_{\mathrm{LD}_{-} \text {Cont }}
$$

Uncontracted generated power by GENCOs, $\Delta \mathrm{P}_{\mathrm{G}_{-} \text {Uncont }}$ is calculated as Eq. (5):

$$
\Delta \mathrm{P}_{\mathrm{G}_{-} \text {Uncont }}=\mathrm{APFM} * \Delta \mathrm{P}_{\mathrm{LD}_{-} \text {Uncont }}
$$

Therefore, total required generation power by each GENCO is visualized in $\Delta \mathrm{P}_{\mathrm{G}}$ matrix, as in Eq. (6):

$$
\Delta \mathrm{P}_{\mathrm{G}}=\Delta \mathrm{P}_{\mathrm{G}_{-} \text {Cont }}+\Delta \mathrm{P}_{\mathrm{G}_{-} \text {Uncont }}
$$

The scheduled tie line power flow between area $i$ and $j$ can be represented as in Eq. (7) and Eq. (8):

$$
\begin{aligned}
\Delta \mathrm{P}_{\mathrm{L}, A \mathrm{i} \rightarrow \mathrm{Aj}} & =\sum_{\mathrm{m}, \mathrm{n}=1}^{\mathrm{M}, \mathrm{N}}\left(\operatorname{cpf}_{\mathrm{mn}} * \Delta \mathrm{P}_{\mathrm{Ld}(\mathrm{n})_{-} \text {Cont }}\right) \\
\Delta \mathrm{P}_{\text {tieij,sch }} & =\Delta \mathrm{P}_{\mathrm{L}, \mathrm{Ai} \rightarrow \mathrm{Aj}}-\Delta \mathrm{P}_{\mathrm{L}, \mathrm{Aj} \rightarrow \mathrm{Ai}}
\end{aligned}
$$

\subsection{Wind Turbine Model for Frequency Regulation}

In this study, the model developed is based on a commercial WPGS model published by GE [10], and its simplified diagram is shown in Fig. 2. A one-mass model is considered for the mechanical drive of the turbine. The mechanical power developed by the turbine is given as Eq. (9):

$$
\mathrm{P}_{\mathrm{M}}=\frac{1}{2} \rho \pi \mathrm{R}^{2} \mathrm{C}_{\mathrm{p}}(\lambda, \beta) \mathrm{v}^{3}
$$




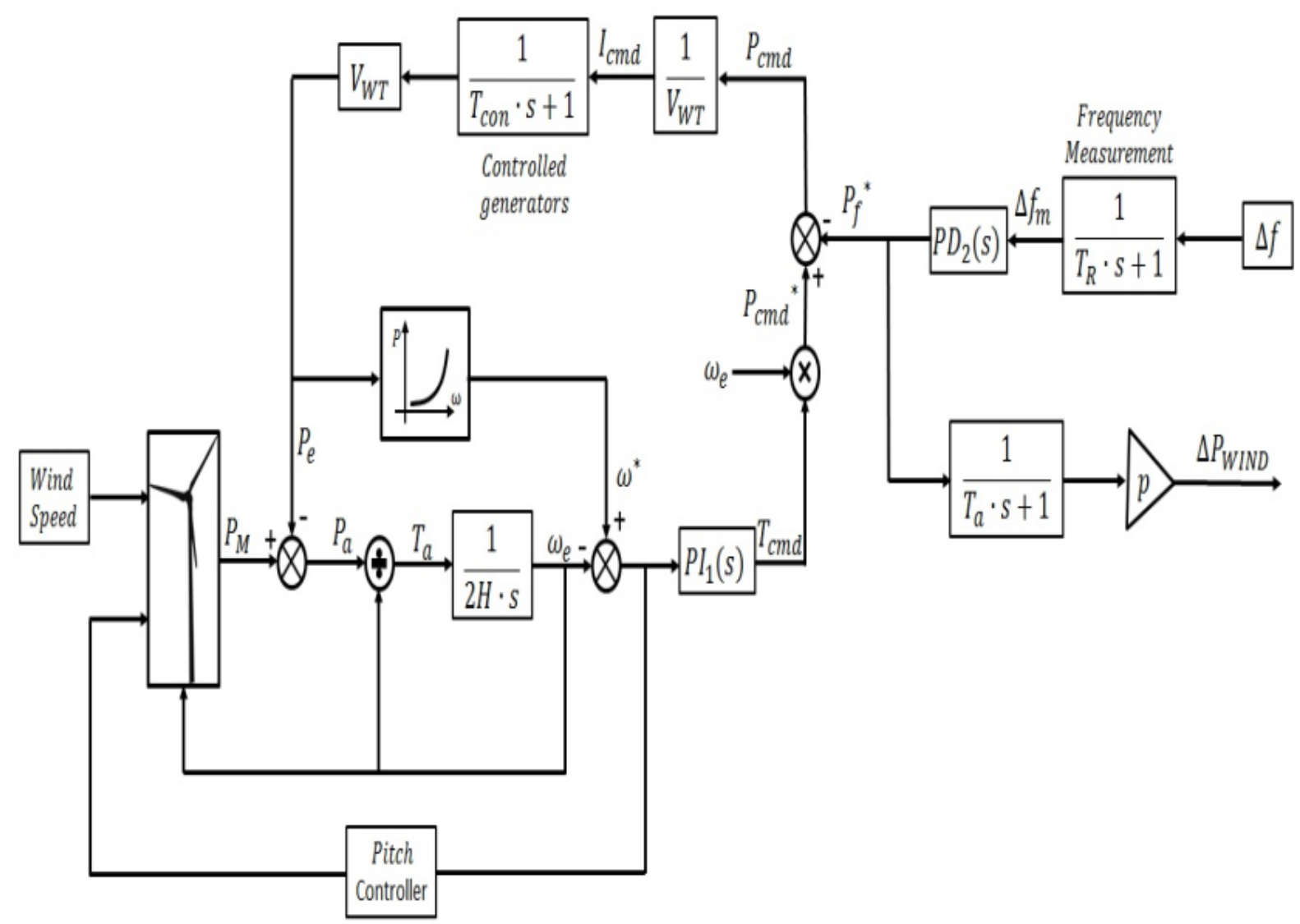

Fig. 2 Simplified block diagram of wind turbine

where $\mathrm{R}$ is the rotor radius, $\rho$ is the air density, $\mathrm{v}$ is the wind speed and $\mathrm{C}_{\mathrm{p}}$ is the power coefficient of the turbine which depends on the pitch angle $\beta$, and the tip-speed ratio $\lambda$, which is defined by Eq. (10):

$$
\lambda=\frac{\mathrm{R} \omega_{\mathrm{e}}}{\mathrm{v}}
$$

where $\omega_{\mathrm{e}}$ is the rotor speed of wind turbine. The power coefficient is a characteristic of the wind turbine, in this study, it can be approximated by Eq. (11):

$$
C_{p}(\lambda, \beta)=\sum_{i=0}^{4} \sum_{j=0}^{4} \alpha_{i, j} \beta^{i} \lambda^{j}
$$

Therefore, it can be concluded that to optimize the amount of power captured by wind turbine the rotor speed and the pitch angle must be controlled. Thus, a reference speed $\omega^{*}$, is generated based on the electric power $\mathrm{P}_{\mathrm{e}}$, for maximum power tracking. The reference is generated as following: the speed is kept at $1.2 \mathrm{pu}$ if the electric power is above $75 \%$, but if the power is reduced below $75 \%$, the reference speed is generates using the following Eq. (12):

$$
\omega^{*}=-0.67 \mathrm{P}_{\mathrm{e}}^{2}+1.42 \mathrm{P}_{\mathrm{e}}+0.51
$$

Then, the generator speed is controlled by a PI controller that has as output the value $\mathrm{P}_{\omega}^{*}$, given by Eq. (13):

$$
\mathrm{P}_{\omega}^{*}=\mathrm{K}_{\mathrm{P}}\left(\omega^{*}-\omega_{\mathrm{e}}\right)+\mathrm{K}_{\mathrm{I}} \int\left(\omega^{*}-\omega_{\mathrm{e}}\right) \mathrm{dt}
$$

The frequency support to the grid, the so-called inertial control must be added to system as explained in [11]. Actually this controller adds to the power reference output signal given by Eq. (14):

$$
\mathrm{P}_{\mathrm{f}}^{*}=-\mathrm{K}_{\mathrm{df}} \frac{\mathrm{d} \Delta \mathrm{f}}{\mathrm{dt}}-\mathrm{K}_{\mathrm{pf}} \Delta \mathrm{f}
$$

where $\mathrm{K}_{\mathrm{df}} \& \mathrm{~K}_{\mathrm{pf}}$ are constants and chosen as weights to the frequency deviation derivative and frequency deviation respectively. By this inertial control mechanism there is an extra increment in the system inertia, so it supports the frequency variation indirectly.

Thus, the total active power reference for wind turbine must be calculates as Eq. (15):

$$
\mathrm{P}_{\mathrm{f} \omega}^{*}=\mathrm{P}_{\omega}^{*}+\mathrm{P}_{\mathrm{f}}^{*}
$$




\section{CONTROL STRATEGIES}

This paper discusses two different optimized control strategies which are implemented on system under study in order to present the comparative analysis. First is integral controller optimized by genetic algorithm and the second is optimized fuzzy controlled system. Later, a comparative analysis is done between the two.

\subsection{Genetic Algorithm Optimized Controller}

In this control strategy, integral controller selected as a controller that is optimized using GA. The controller input is $A_{C E}, K_{i x}$ is inertial gain of controller and $u_{x}$ is output of controller in control area-x [12-13], as shown in Eq. (16);

$$
u_{x}=-K_{i x} \int A C E_{x} d t
$$

GA is an evolutionary algorithm based on natural genetics mechanics, capable to generate optimal solutions [14]. In order to get optimum results, integral gain $\left(\mathrm{K}_{\mathrm{i}}\right)$ achieved using GA in which ISE function is used as fitness function, as per Eq. (17);

$$
J_{I S E}=\int_{0}^{T}\left(\triangle A C E_{1}{ }^{2}+\triangle A C E_{2}{ }^{2}\right) d t
$$

$\mathrm{T}$ is minimum simulation time, where system is stable. Optimization converges and the values of $\mathrm{K}_{\mathrm{i}}$ gain for both controllers obtained are shown in Table 1.

\begin{tabular}{lcl}
\multicolumn{3}{c}{ Table 1 Integral gains with GA in both Areas } \\
\hline & $\mathrm{K}_{\mathrm{i} 1}$ & \multicolumn{1}{c}{$\mathrm{K}_{\mathrm{i} 2}$} \\
\cline { 2 - 3 } GAI without WPGS support & 0.37533 & 0.10 \\
GAI with WPGS support & 0.90579 & 0.11033 \\
\hline
\end{tabular}

\subsection{Fuzzy Logic Controller Design}

FLC is a successful control technique for uncertain and nonlinear complex systems and widely accepted as alternatively approach to conventional approach to many engineering applications. In complex and multivariable power system, conventional control strategies may not give satisfactory solutions. FLC modelling consists of three steps of fuzzification, formation of fuzzy control rule base and defuzzification.

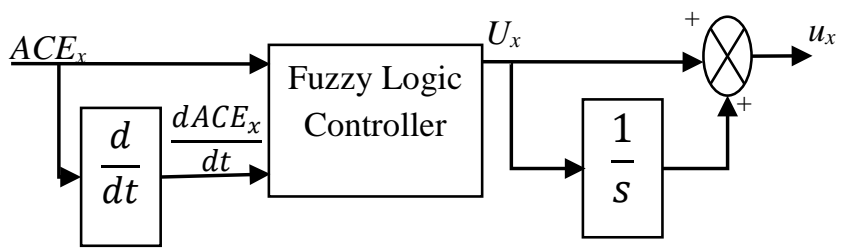

Fig. 3 MISO type FLC

This FLC designed based on MISO type with two inputs and one output. The first input is $\mathrm{ACE}_{\mathrm{i}}$ and another one is derivative of $\operatorname{ACE}_{x}\left(\frac{d A C E_{x}}{d t}\right)$ and $u_{x}$ is output control signal as shown in Fig 3. Table 2 presents the view of rules for fuzzy logic controller utilized to design controller. There are seven triangular membership functions and centroid as defuzzification technique is considered [15].

\begin{tabular}{|c|c|c|c|c|c|c|c|c|}
\hline \multicolumn{9}{|c|}{$\triangle \mathrm{ACE}$} \\
\hline \multirow{8}{*}{ 甹 } & & VVL & VL & $\mathrm{L}$ & $\mathrm{Z}$ & $\mathrm{H}$ & $\mathrm{VH}$ & VVH \\
\hline & VVL & VVL & VVL & VL & VL & $\mathrm{L}$ & $\mathrm{L}$ & $\mathrm{Z}$ \\
\hline & VL & VVL & VL & VL & $\mathrm{L}$ & $\mathrm{L}$ & $\mathrm{Z}$ & $\mathrm{H}$ \\
\hline & $\mathrm{L}$ & VL & VL & $\mathrm{L}$ & $\mathrm{L}$ & $\mathrm{Z}$ & $\mathrm{H}$ & $\mathrm{H}$ \\
\hline & $\mathrm{Z}$ & VL & $\mathrm{L}$ & $\mathrm{L}$ & $\mathrm{Z}$ & $\mathrm{H}$ & $\mathrm{H}$ & $\mathrm{VH}$ \\
\hline & $\mathrm{H}$ & $\mathrm{L}$ & $\mathrm{L}$ & $\mathrm{Z}$ & $\mathrm{H}$ & $\mathrm{H}$ & $\mathrm{VH}$ & $\mathrm{VH}$ \\
\hline & $\mathrm{VH}$ & L & $\mathrm{Z}$ & $\mathrm{H}$ & $\mathrm{H}$ & VH & VH & VVH \\
\hline & VVH & Z & $\mathrm{H}$ & $\mathrm{H}$ & VH & VH & VVH & VVH \\
\hline
\end{tabular}

Table 2 Rule base for FLC

\section{SIMULATION TEST CASES}

Simulations have been conducted in a two area thermal-hydro power system with FLC and Integral controller optimized by GA. There are three test cases taken where first case is with step load disturbance, which is subjected on thermal-hydro system. Second with varying load profile, while the third to observe the effect of wind penetration on various combinations of conventional plants. Matlab/Simulink is used for simulation purpose. 


\subsection{Test Case A: Step Load}

For test cases A \& B all the DISCOs contract power with the GENCOs. Each DISCO demands pu MW power from GENCOs as defined by cpf's in cpf_matrix and each GENCO participates in automatic generation control as defined by following apf: apf1 $=0.5$, apf2 $=0.5$; apf $3=0.5$, apf $4=0.5$; and CPFM is:

$$
\begin{gathered}
C P F M=\left[\begin{array}{llll}
0.5 & 0.5 & 0.0 & 0.0 \\
0.5 & 0.5 & 0.0 & 0.0 \\
0.0 & 0.0 & 0.5 & 0.5 \\
0.0 & 0.0 & 0.5 & 0.5
\end{array}\right] ; \\
\Delta P_{\text {LD_Uncont }}=\left[\begin{array}{l}
0.00 \\
0.00 \\
0.00 \\
0.00
\end{array}\right] ; \Delta P_{L D}=\left[\begin{array}{l}
0.05 \\
0.05 \\
0.05 \\
0.05
\end{array}\right] ;
\end{gathered}
$$

In this simulated case demanded load power is within contract limit. To meet load demand, power to be generated is given by:

$$
\Delta P_{G}=\left[\begin{array}{l}
0.05 \\
0.05 \\
0.05 \\
0.05
\end{array}\right]
$$

Peak undershoot and settling time are dynamic parameters to analysis the performance of controllers when it is subjected to step perturbation. Table 3 shows comparison of controllers on the basis of performance parameters with and without frequency support from WPGS.

Table 3 Comparison of GAI and FLC Controller with or without wind with step load change

\begin{tabular}{llllll}
\hline & & \multicolumn{2}{c}{ WPGS Without Freq. Support } & \multicolumn{2}{c}{ WPGS With Freq. Support } \\
\cline { 3 - 6 } Peak_Undershoot & GAI & FLC & -0.004530 & -0.001909 & -0.001181 \\
\cline { 2 - 6 } & Area1_freq. & -0.006244 & -0.024468 & -0.008426 & -0.008955 \\
& Area2_freq. & -0.024975 & -0.013099 & -0.017579 & -0.003104 \\
& P_Tieline & -0.019263 & 50.959788 & 43.068700 & 8.795149 \\
& Area1_freq. & 61.114581 & 44.819118 & 34.009168 & 11.039225 \\
& Area2_freq. & 49.695922 & $>100$ & $>100$ & 69.172200 \\
\hline
\end{tabular}




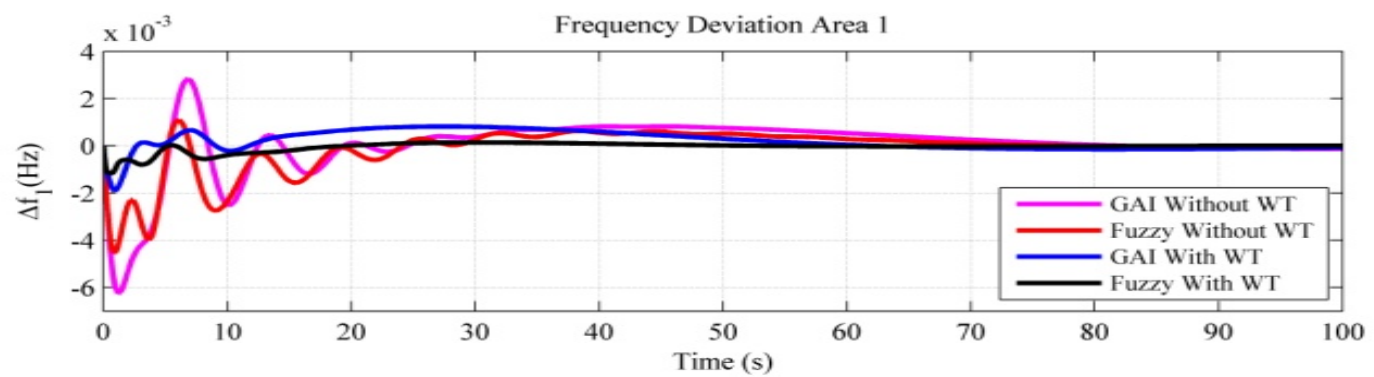

Frequency Deviation Area 2
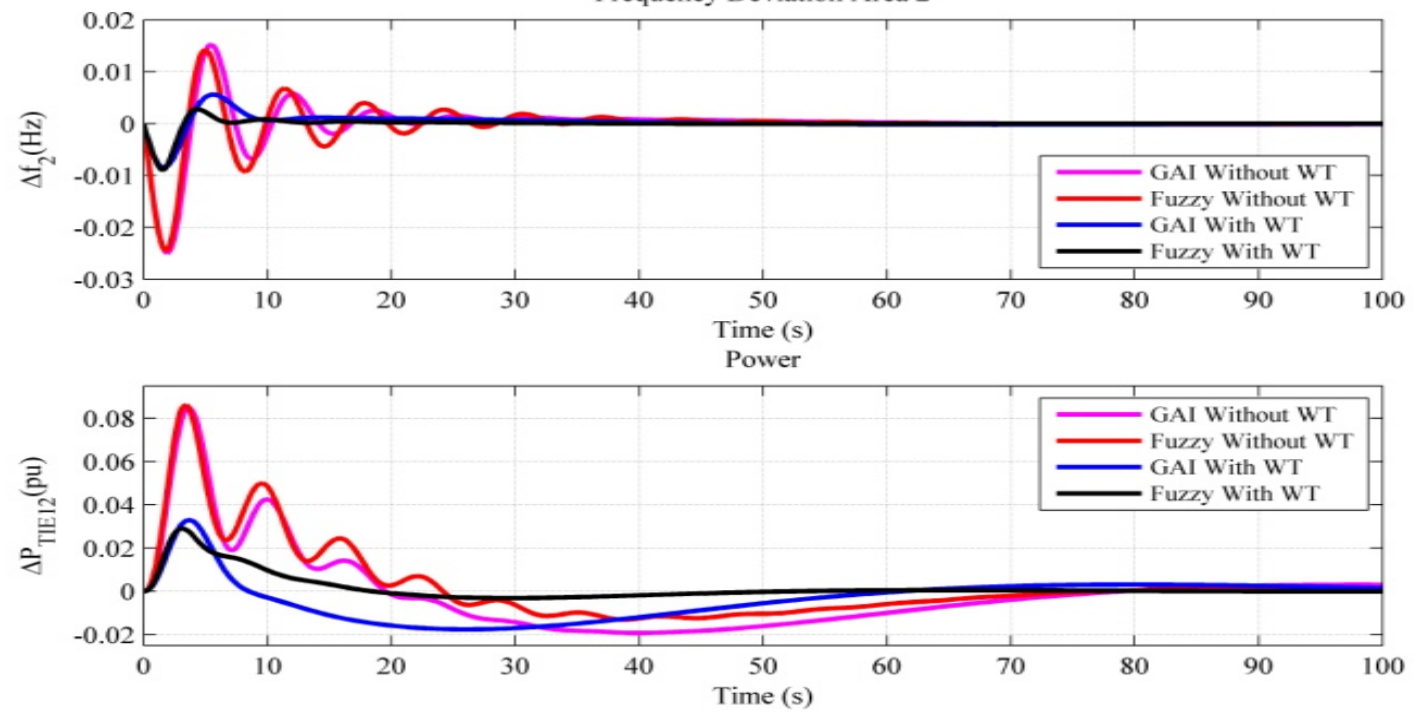

Fig. 44 Comparison of GAI without wind, GAI with wind, FLC without wind and FLC with wind at nominal values of system parameters with step load change (a) frequency deviation in area 1, (b) frequency deviation in area 2, (c) tie-line power deviation

\subsection{Test Case B: Varing load with different level of penetration}

To evaluate the performance of proposed controller with and without wind power input variable step load transient responses are obtained. The variable load profile is shown in Fig 5.

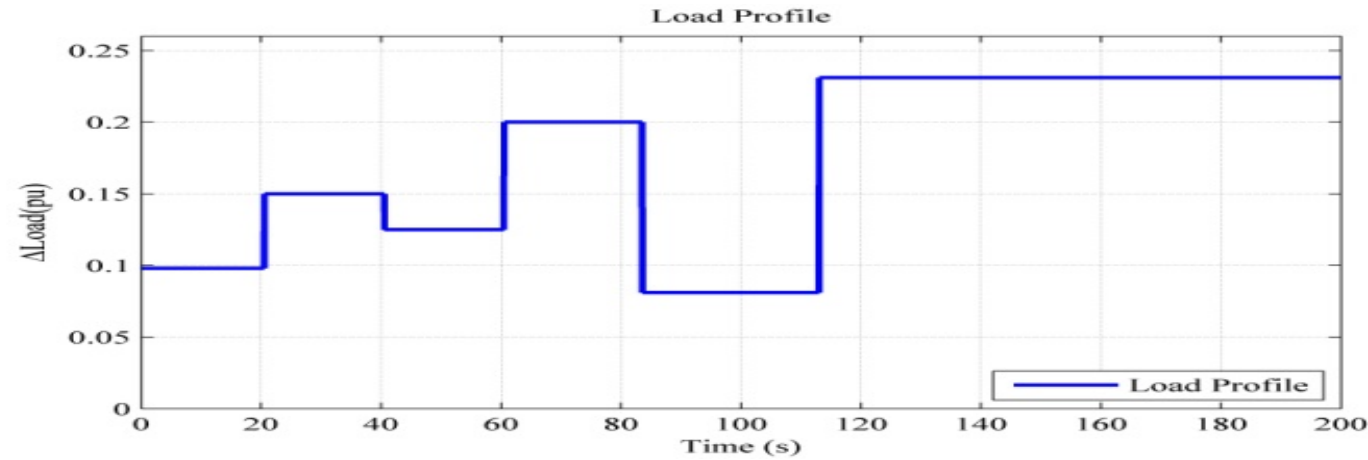

Fig. 5 Variable Load change profile for which comparison done at 10\%, 15\% and 20\% penetration 
Frequency Deviation Area 1

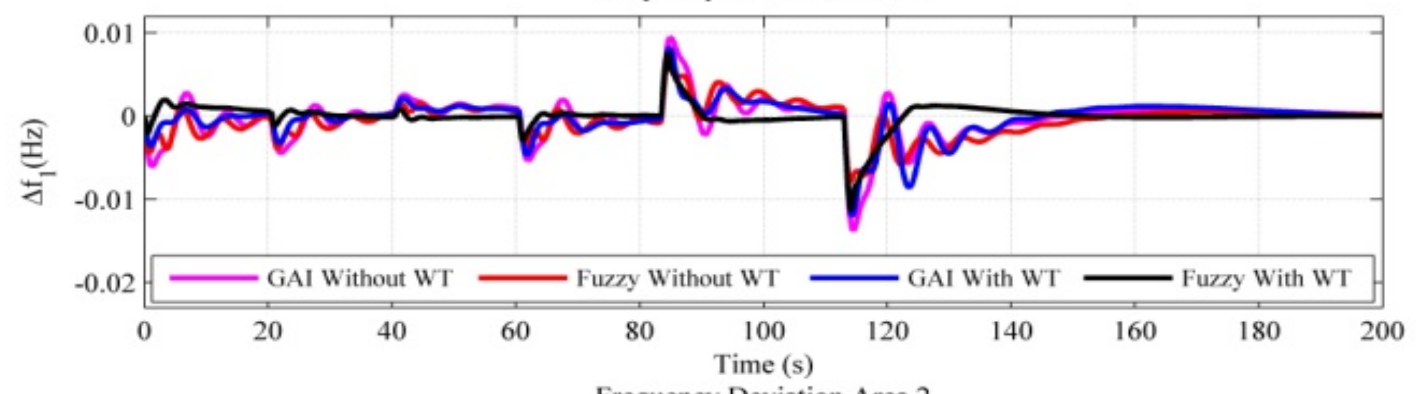

Frequency Deviation Area 2
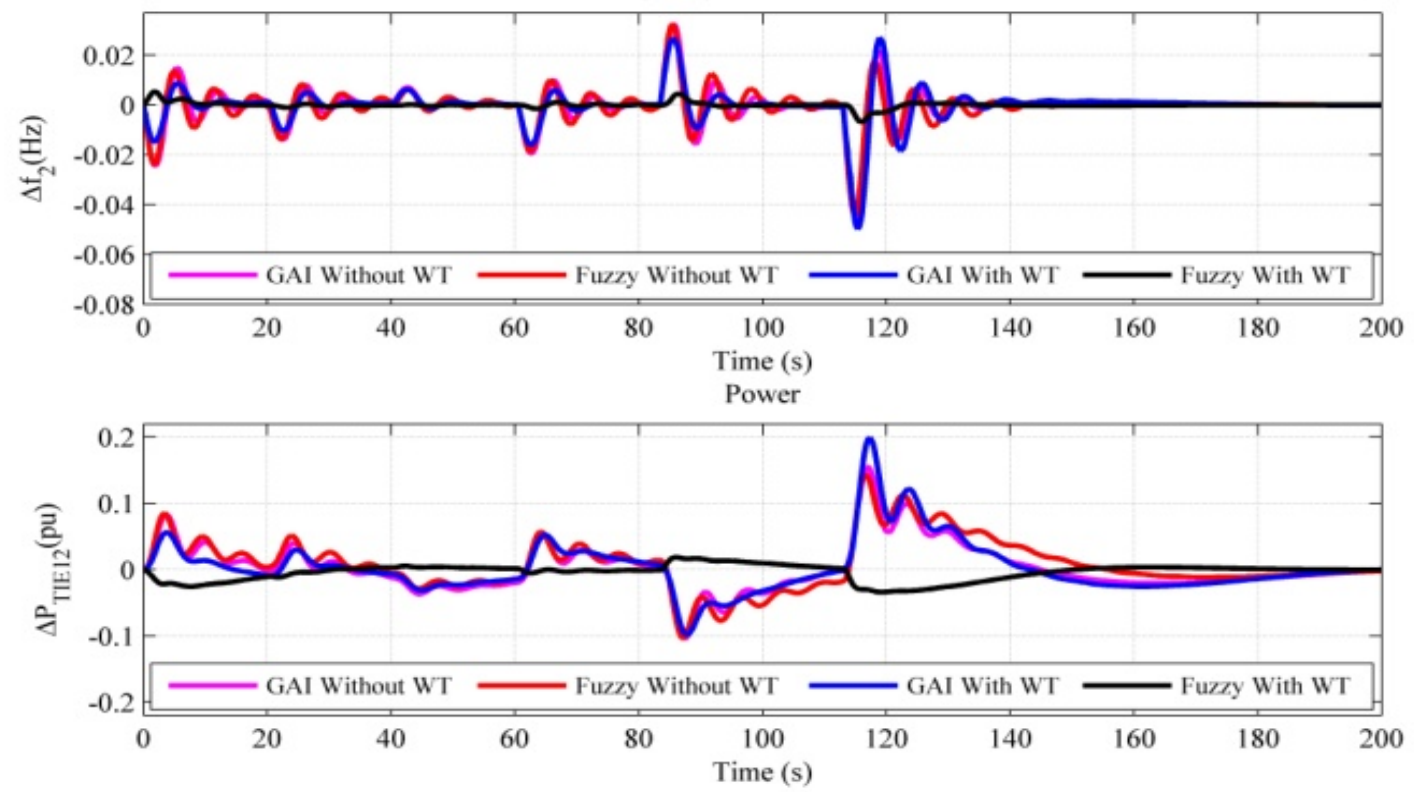

Fig. 66 10\% wind penetration with varying load (a) frequency deviation in area 1, (b) frequency deviation in area 2, (c) tie-line power deviation 

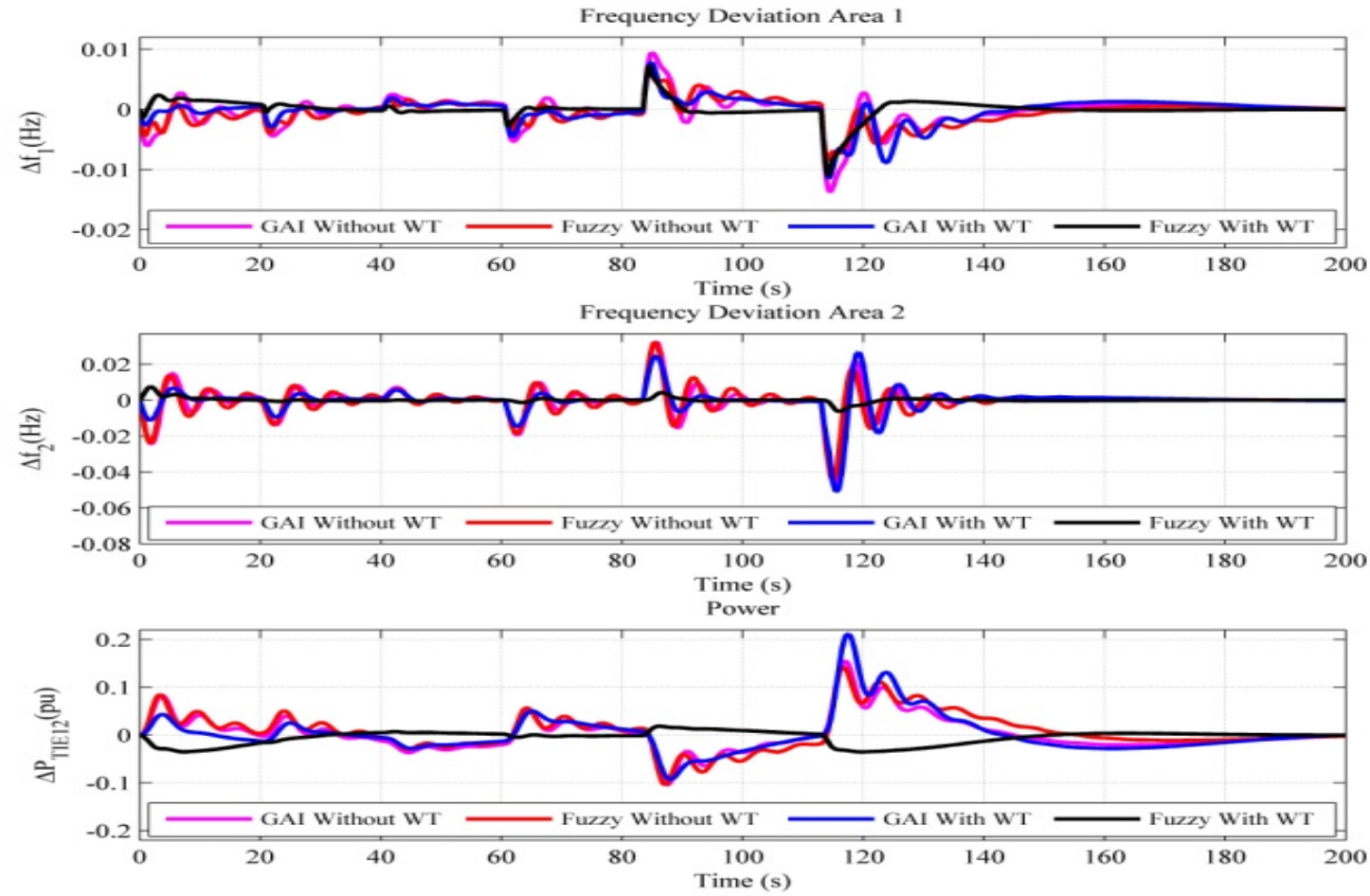

Fig. 7 15\% wind penetration with varying load (a) frequency deviation in area 1, (b) frequency deviation in area 2, (c) tie-line power deviation
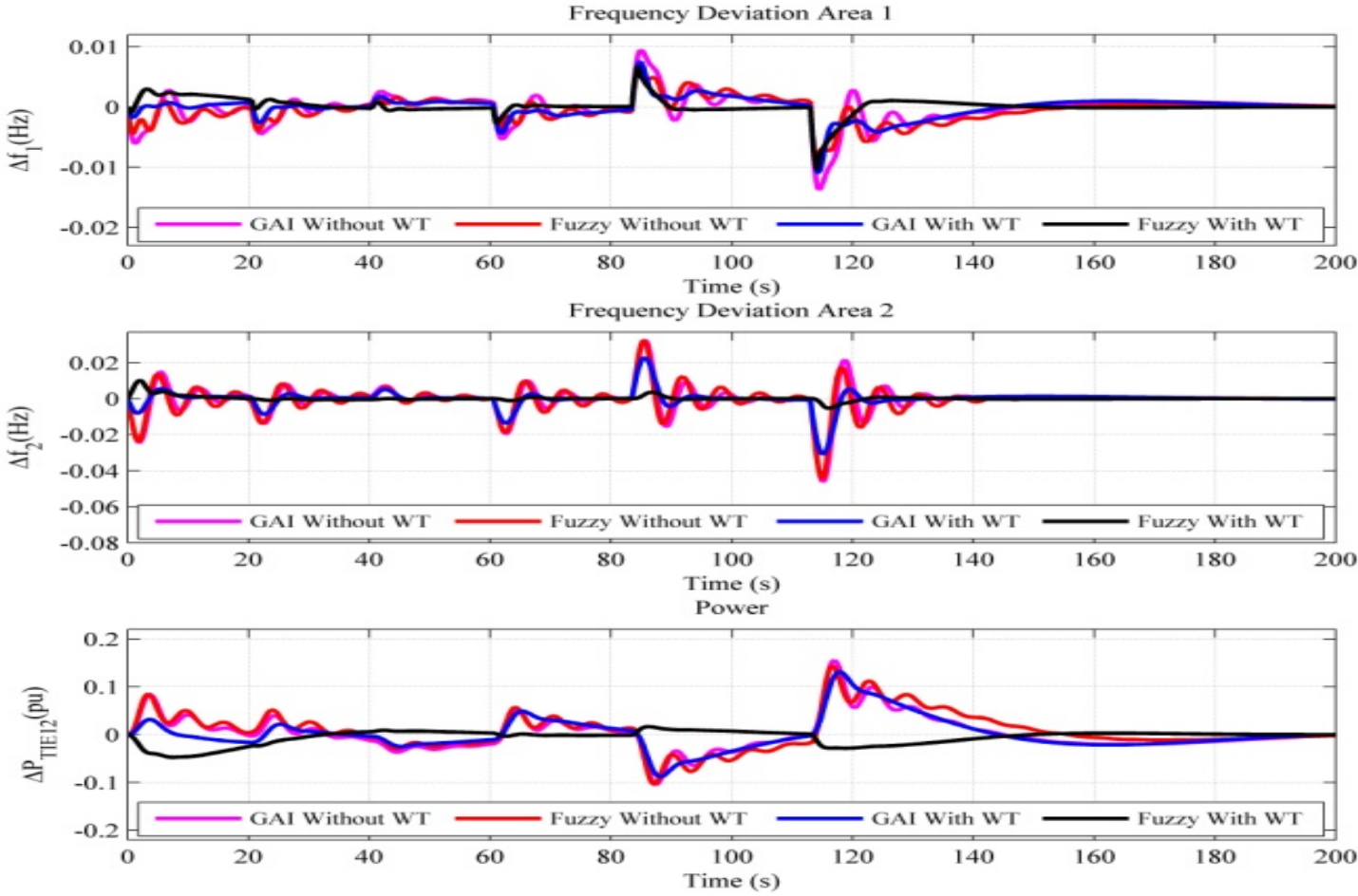

Fig. 8 20\% wind penetration with varying load (a) frequency deviation in area 1, (b) frequency deviation in area 2, (c) tie-line power deviation 


\subsection{Test Case C: Different combinations of GENCOs}

In our study, four different combinations are taken and each area has two similar generating units. The combinations are (i) Thermal-Thermal with wind power connected in area 2 (TT-TTW) (ii) Thermal-Thermal with wind power connected in both areas (TTW-TTW) (iii) Thermal-Hydro with wind power connected in area 2 (TT-HHW) and (iv) Thermal-Hydro with wind power connected in both areas (TTW-HHW). Further, the impact of wind power penetration in each of the cases is simulated and analysed. Step disturbance is impressed in all four cases.

\subsubsection{Test Case C.1 (TT-TTW)}

In this case, a two area system with thermal-thermal units, wind power is fed in area 2 only, as per Fig. 9. The simulation results are shown in Fig. 10. It is observed that deviation in area 1 frequency is not having substantial impact as compared to deviation in area 2 frequency. Area 2 is getting benefitted with this distributed generation planning more than area 1, due to WPGS frequency support. The tie line power is zero initially as load on both the areas is balanced, but as wind penetration increases tie line starts carrying more and more power.
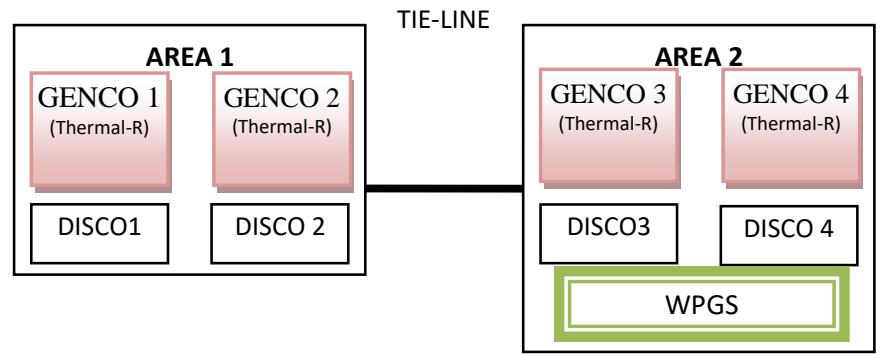

Fig. 8 A interconnected two Areas, Area-1 consist of thermal \& thermal power system and Area-2 consist of thermal \& thermal power system with WPGS in Area-2
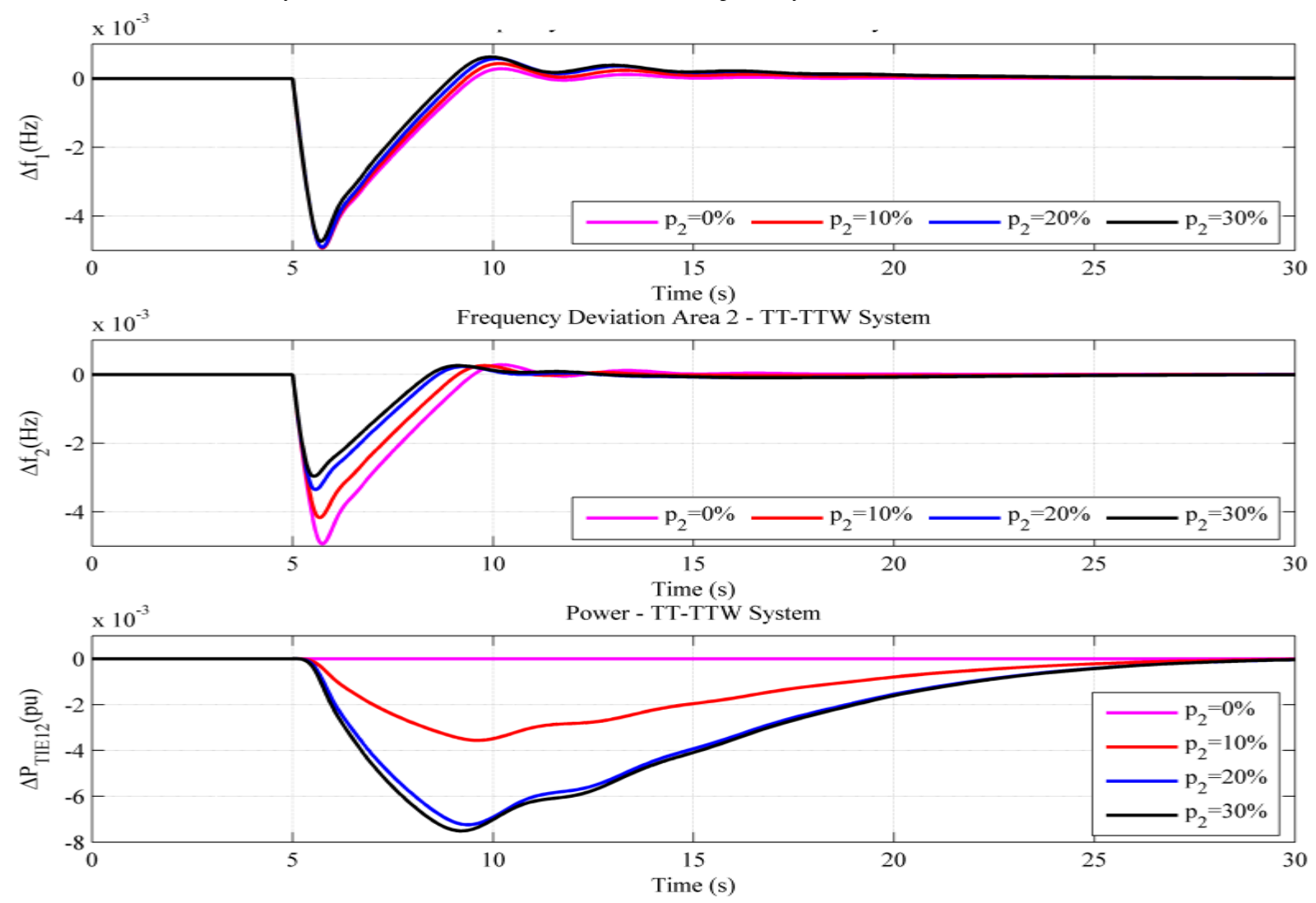

Fig. 9 Simulation results of case C.1 i.e. TT-TTW

\subsubsection{Test Case C.2 (TT-HHW)}

In this case of thermal-hydro system, the WPGS is integrated in area 2 only, as per Fig. 11. The effect is quite visible of increasing wind power in area 2. The fast and smoother stabilization of frequency deviation in both areas as well as tie-line power are visible in results shown in Fig. 12. It could be because of fuzzy controller used in the system. 


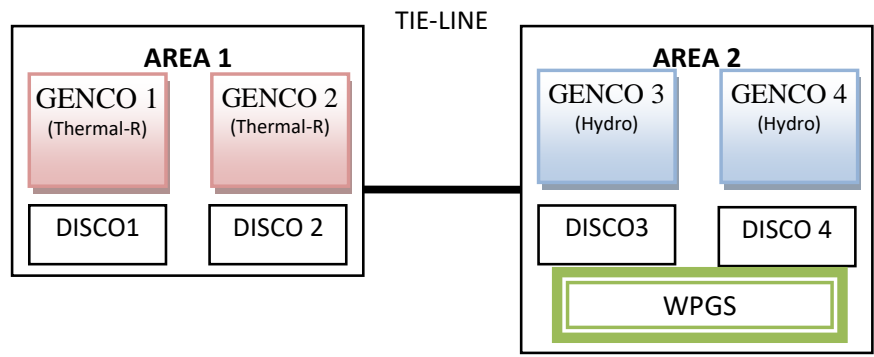

Fig. 10 A interconnected two Areas, Area-1 consist of thermal \& thermal power system and Area-2 consist of hydro \& hydro power system with WPGS in Area-2

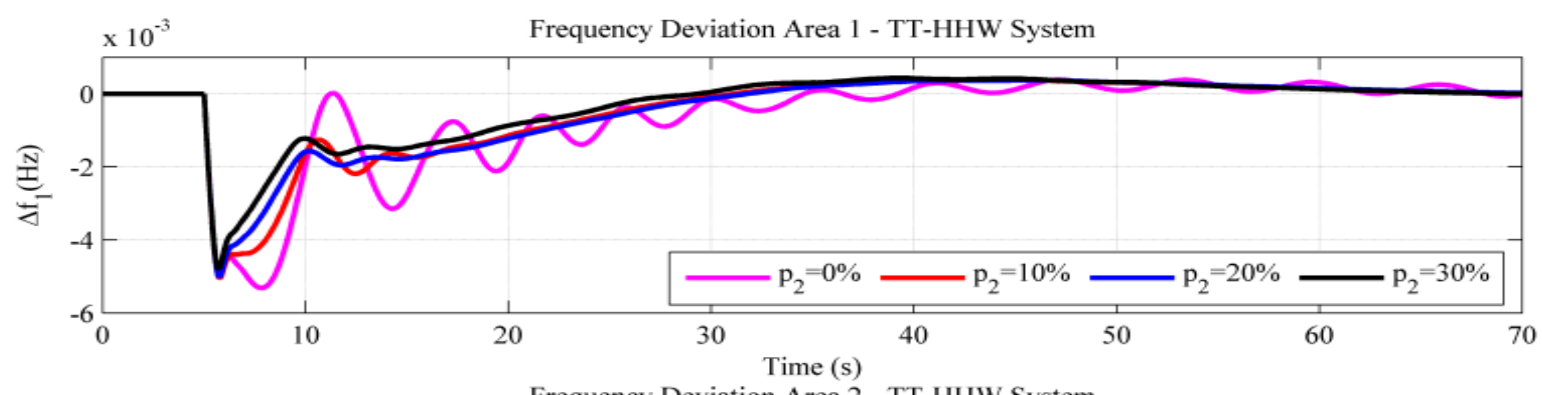

Frequency Deviation Area 2 - TT-HHW System
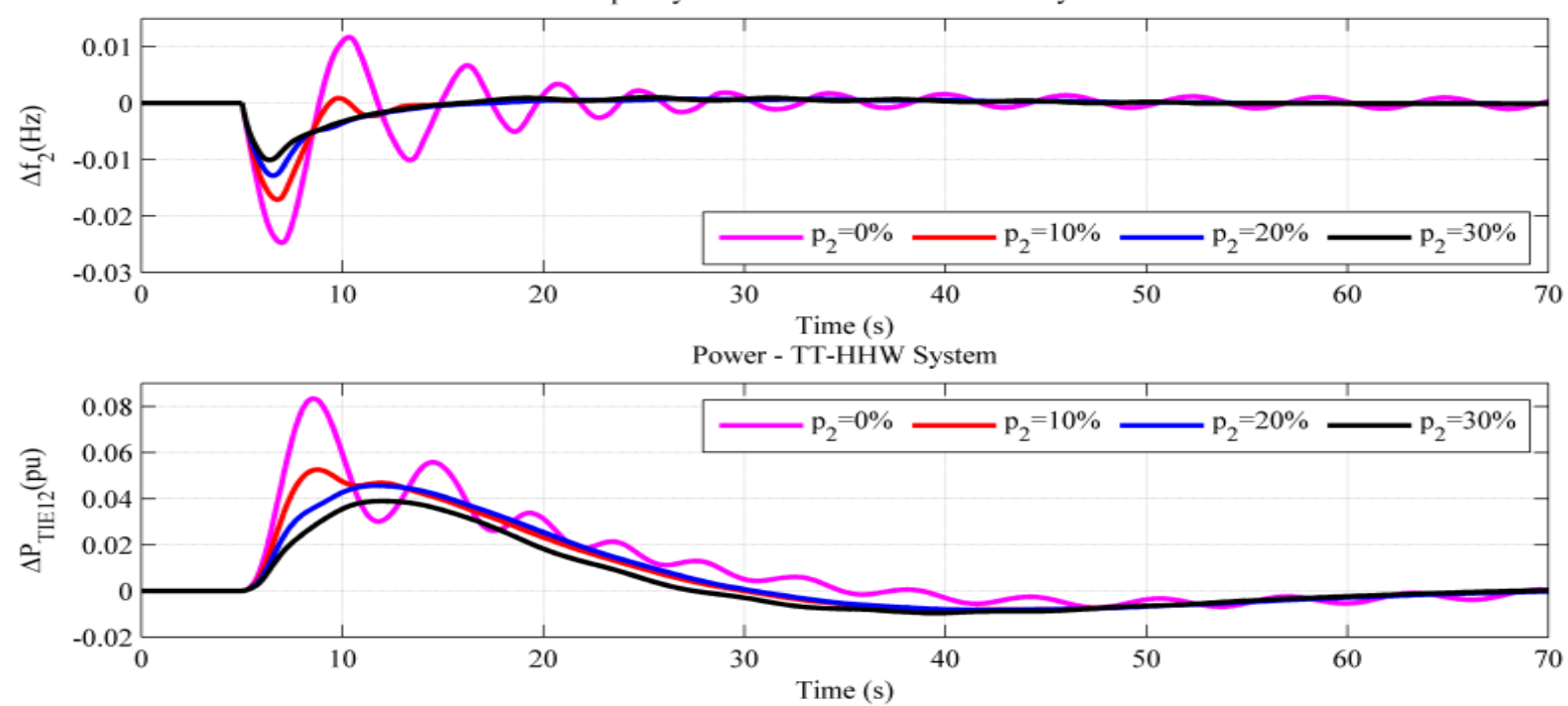

Fig. 11 Simulation results of case 2 i.e. TT-HHW

\subsubsection{Test Case C.3 (TTW-TTW)}

In this situation where both the areas are consisting of similar units of same ratings and loading is also given same, tie-line will not carry any power as there is no deviation. Since wind energy is fed into both areas, frequency deviation is substantially supported and helping to improve better power quality. The results are shown in Fig. 14.

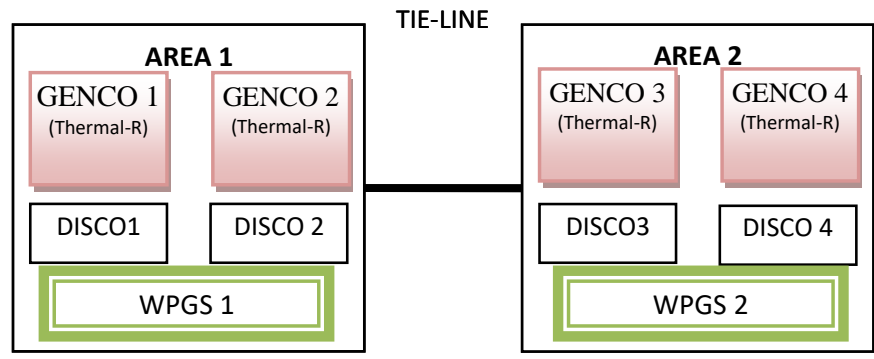

Fig . 12 A interconnected two Areas, Area-1 consist of thermal \& thermal power system and Area-2 consist of thermal \& thermal power system with WPGS in both Areas 


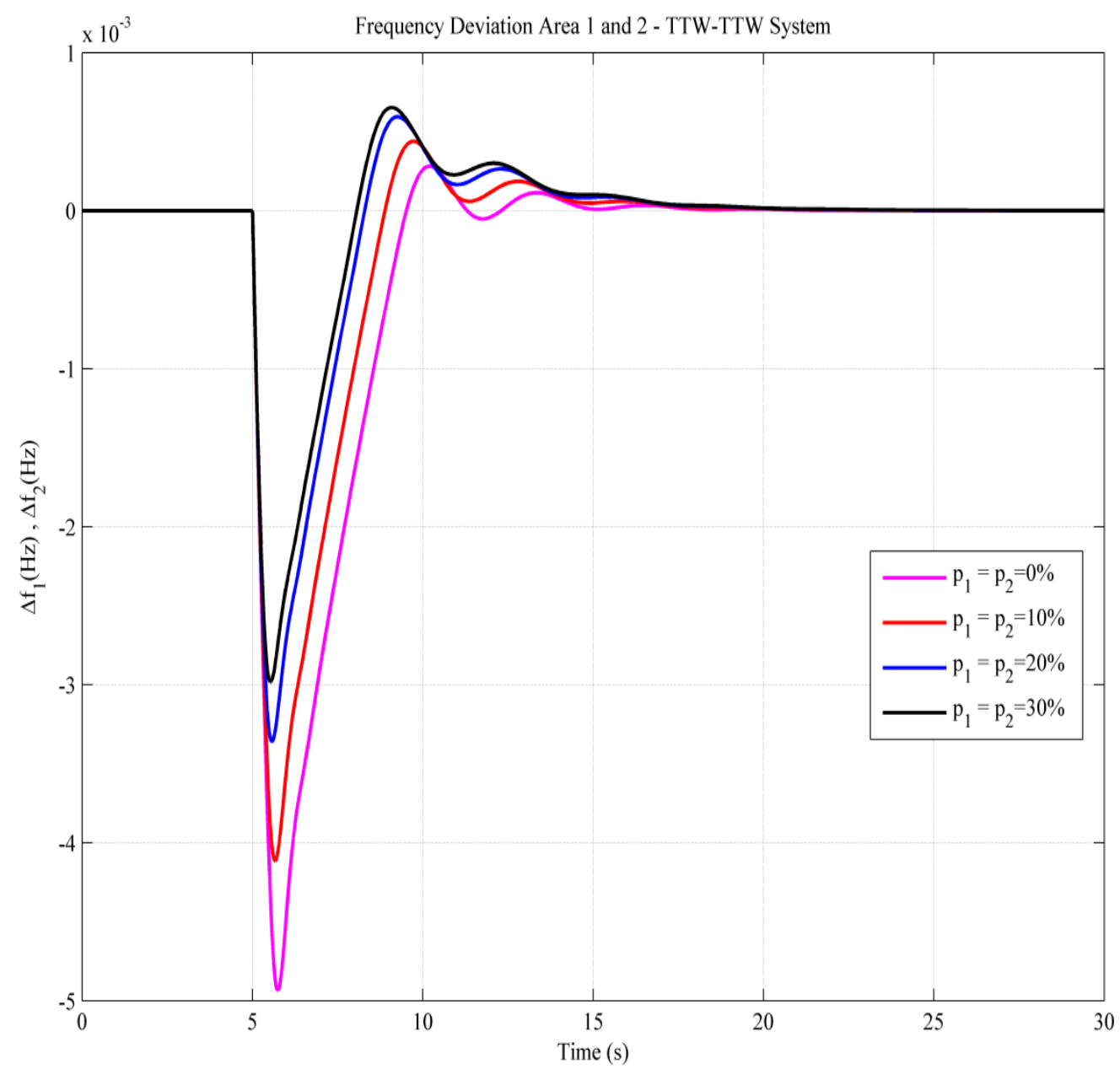

Fig. 13 Simulation results of case 3 i.e. TTW-TTW

\subsubsection{Test Case C.4 (TTW-HHW)}

In this last case study, wind power is penetrated into both the areas with equal penetration level, as in Fig.15. This result is shown in Fig. 16. Not only frequency deviations in area 1 and area 2 get better profile with more penetration but tie-line power flow is smooth and fast. With wind power, system frequencies keep oscillating for quite a long time which is always undesirable for grid stability.

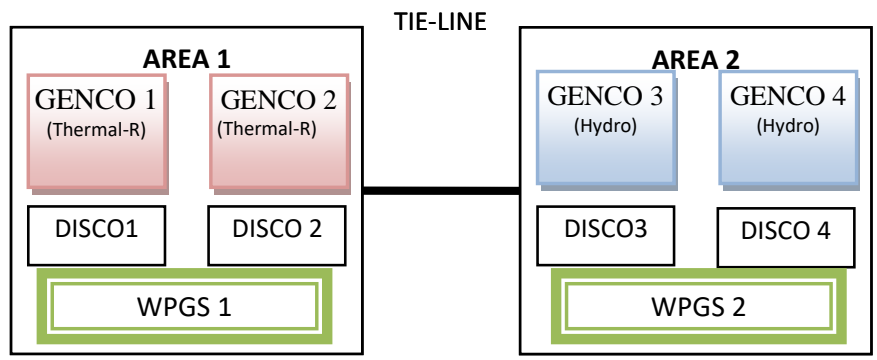

Fig. 14 A interconnected two Areas, Area-1 consist of thermal \& thermal power system and Area-2 consist of hydro \& hydro power system with WPGS in both Area-1 \& 2 

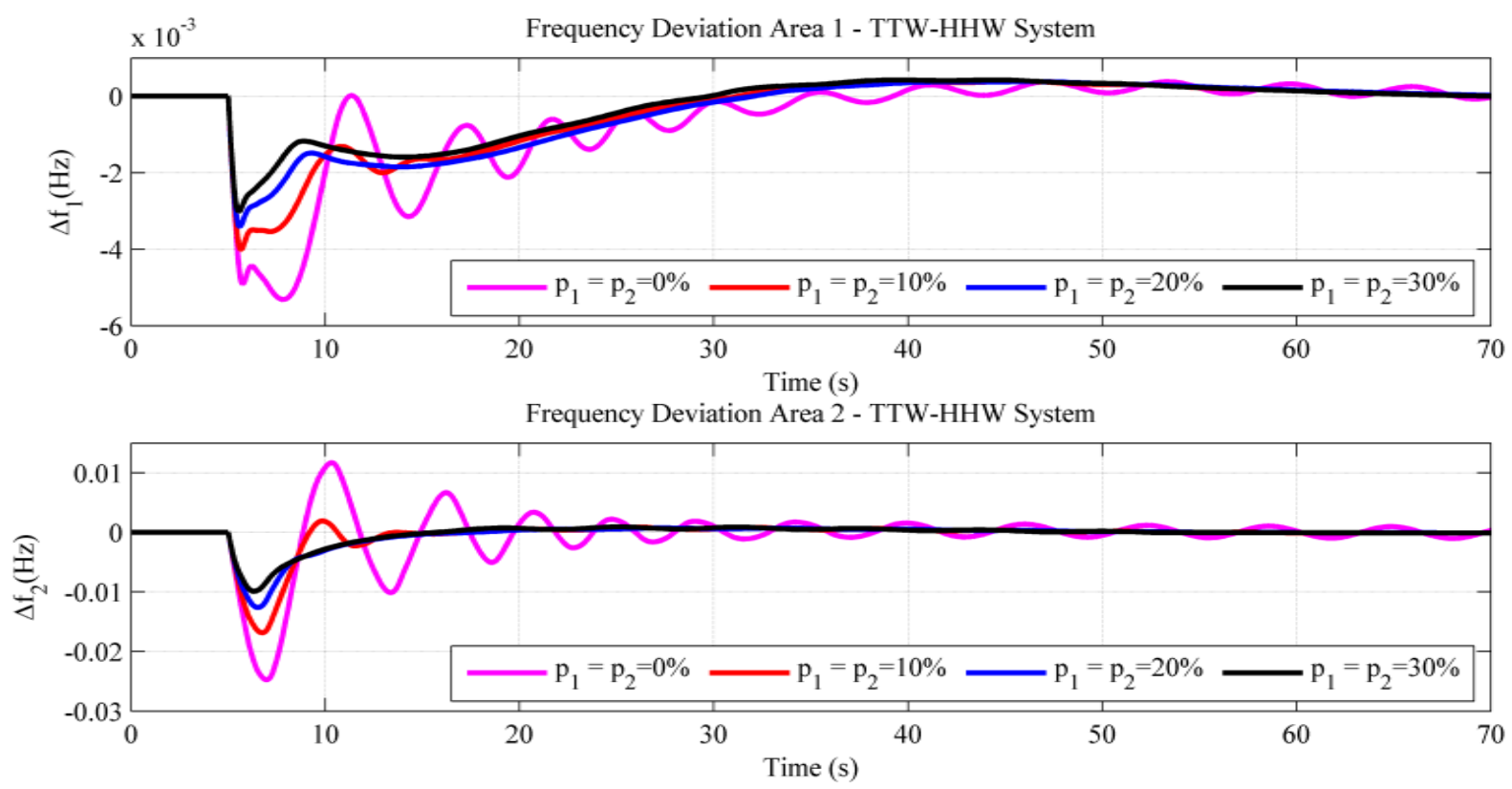

Power - TTW-HHW System

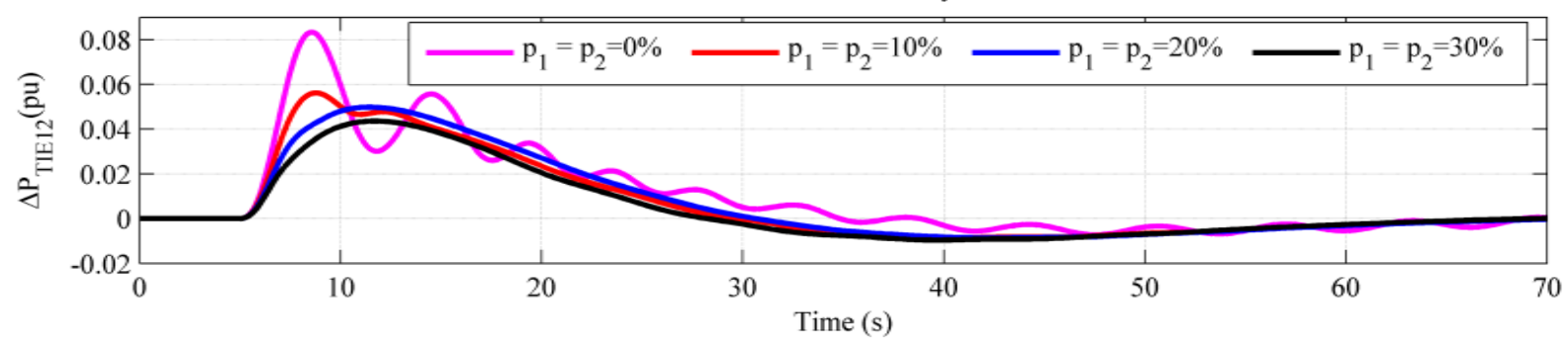

Fig. 15 Simulation results of case 4 i.e. TTW-HHW

\section{RESULTS AND DISCUSSION}

Frequency deviations of both areas and tie line deviation at step load perturbation as per test case A. shown in Fig. 4. The results obtained justify the stability and effectiveness of the proposed controller. The comparison of dynamic performances of the proposed FLC with wind support shows better results than GAI with wind support. Different levels of wind penetration are applied for simulation and assumed wind speed is constant. As per simulation results, major dynamic performance parameters i.e. peak undershoot and settling time are better with fuzzy controller as compared to GA optimized integral controller.

The varying load scenario is a practical situation therefore, in test case B frequency deviations of both areas and tie line deviation obtained for varying load at different wind penetrations. The results show again the robustness of the proposed controller. Frequency deviations of both areas and tie line deviation at variable load as per test case B. are shown in Fig. 6, 7 and 8 for 10\%, 15\% and 20\% wind penetration in area 1 and area 2 respectively. So, not even in step disturbance but also in varying load perturbations, proposed FLC with wind support shows better results for different levels of wind penetration.

In test case C, different combination of GENCOs with WPGS frequency support examined for different wind penetration. In this test case, frequency deviations of both areas and tie line deviation are shown in Fig. 10, 12, 14, and 16 for all four different cases. In test case C.1, it is observed that active power support is given in area 2 and it is only getting benefitted in managing its load. This observation justifies the distributed generation strategy to have better local support. In test case C.2, where areas are equipped with different types of generating units, oscillations are bound to happen when areas are subjected to load disturbance. In test case C.3, where areas are equipped with same types of generating units with individually connected by WPGS, frequency deviations in both areas are again effectively mitigated by WPGS when areas are subjected to load disturbance. In test case C.4, frequency deviations in both areas get better suppressed by WPGS with more penetration and tie-line power flow is also smooth and fast. Fuzzy controller in all the cases helps in making the transient situation smoother and faster. This ultimately helps in improving grid discipline and stability. Therefore, it is 
seen that without wind penetration oscillations persists for a longer time but as soon as penetration level is increased the deviation is less and settlement is faster and smoother.

\section{CONCLUSION}

This paper analyses the participation of WPGS in inertial support for reducing frequency and tie-line power oscillations for different set of combination of varying wind power penetration, varying load, and integration with various combinations of conventional sources. For fast frequency response the WPGS based wind energy system releases the kinetic energy stored in its rotating masses. Simulation studies for step load and varying load perturbations have been conducted in a two-area interconnected power system in deregulated environment which demonstrates the contribution of the wind power in inter-area oscillation suppression in terms of frequency deviations in each area and tie-line power. The proposed control scheme with fuzzy logic uses frequency deviations to provide fast active power support, which mitigates the oscillation in frequency and tieline power during transient conditions. Wind power with increased penetration validates the current focus of global strategies of including more and more renewable sources particularly wind as it provides short term active power support by increasing inertia of whole system and helps in managing the instant load demand.

\section{References}

[1] Ekanayake J, Jenkins N. Comparison of the Response of Doubly Fed and Fixed-Speed Induction Generator Wind Turbines to Changes in Network Frequency. IEEE Trans. ENERGY Convers. 2004;19(4):800-802.

[2] Rabelo B, Hofmann W. Optimal active and reactive power control with the doubly-fed induction generator in the MW-class wind-turbines. 4th IEEE Int. Conf. Power Electron. Drive Syst. IEEE PEDS 2001 - Indones. Proc. (Cat. No.01TH8594). 2001;1.

[3] Slootweg JG, Haan SWH De, Polinder H, Kling WL. General Model for Representing Variable Speed Wind Turbines in Power System Dynamics Simulations. IEEE Trans. power Syst. 2003;18(1):144-151.

[4] Lalor G, Ritchie J, Rourke S, Flynn D, O’Malley MJ. Dynamic frequency control with increasing wind generation. IEEE Power Eng. Soc. Gen. Meet. 2004. 2004.

[5] Almeida RG De, Lopes JAP. Participation of Doubly Fed Induction Wind Generators in System Frequency Regulation. IEEE Trans. power Syst. 2007;22(3):944-950.

[6] Mullane A, Malley MO. The Inertial Response of Induction-Machine-Based Wind Turbines. IEEE Trans. power Syst. 2005;20(3):1496-1503.

[7] Tan, W., Zhang, H., \& Yu, M. (2012). Electrical Power and Energy Systems Decentralized load frequency control in deregulated environments. International Journal of Electrical Power and Energy Systems, 41(1), 16-26.

[8] Kundur P. Power System Stability and Control.; 2006:739.

[9] Bhatt P, Roy R. Optimized Automatic Generation Control by SSSC and TCPS in Coordination with SMES for Two-area Hydro-Hydro Power System. In: 2009 International Conference on Advances in Computing, Control, and Telecommunication Technologies (2009).; 2009:474-480.

[10] Miller NW, Price WW, Sanchez-gasca JJ. Dynamic Modeling of GE 1 . 5 and 3.6 Wind Turbine-Generators.; 2003.

[11] Marano A, Gomez-Exposito A, Martinez Ramos JL, Mauricio JM. Frequency Regulation Contribution Through Variable-Speed Wind Energy Conversion Systems. IEEE Trans. Power Syst. 2009;24:173-180.

[12] Nanda J, Mishra S, Saikia LC. Maiden Application of Bacterial Foraging-Based Optimization Technique in Multiarea Automatic Generation Control. IEEE Trans. power Syst. 2009;24(2):602-609.

[13] Roy R, Ghoshal SP, Bhatt P. Evolutionary computation based four-area automatic generation control in restructured environment. Power Syst. 2009. ICPS '09. Int. Conf. 2009.

[14] Goldberg DE. Genetic Algorithms in Search, Optimization, and Machine Learning.; 1989:432.

[15] Cam E, Kocaarslan I. Load frequency control in two area power systems using fuzzy logic controller. Energy Convers. Manag. 2005;46:233-243.

\begin{tabular}{ll}
\multicolumn{1}{c}{ Appendix: System Parameters } \\
\hline Rating (MW) & 2000 \\
\hline Tg1,Tg2,Tg3 and Tg4 (sec) & 0.08 \\
Tt1,Tt2,Tt3 and Tt4 (sec) & 0.3 \\
Tr1,Tr2,Tr3 and Tr4 (sec) & 10 \\
Kr1,Kr2,Kr3 and Kr4 & 0.5 \\
b1,b2,b3 and b4 & 0.425 \\
R1,R2,R3 and R4 & 2.4 \\
Kp1,Kp2,Kp3 and Kp4 & 120 \\
Tp1,Tp2,Tp3 and Tp4 (sec) & 20 \\
T12 & 0.545 \\
a12 & -1 \\
Tr1, Tr2 & 5 \\
Tw1, Tw2 & 1 \\
Rp1, Rp2 & 0.05 \\
Rt1, Rt2 & 0.38 \\
\hline
\end{tabular}

